\title{
Normal Sinus Rhythm
}

National Cancer Institute

\section{Source}

National Cancer Institute. Normal Sinus Rhythm. NCl Thesaurus. Code C102681.

An electrocardiographic finding of an atrial rhythm which originates from the sinoatrial

node that is considered normal for the population. There are no extra beats or

conduction abnormalities. (CDISC) 